Jurnal HELPER, Vol 36 No 1 (2019) 21 - 26

Bimbingan dan Konseling Universitas PGRI Adi Buana Surabaya

\title{
MEREDUKSI KECANDUAN SMARTPHONE MELALUI LAYANAN KONSELING INDIVIDU DENGAN TEKNIK KONTRAK PERILAKU SISWA XII TEI 1 SMKN 1 BANDUNG KABUPATEN TULUNGAGUNG
}

\author{
Prabandari Nuansmahira \\ SMK Negeri 1 Bandung Tulungaggung \\ pnuansmahira6@gmail.com \\ Dewi Nurmalika \\ SMA NU Gombengsari \\ bimaabda28@gmail.com
}

\begin{abstract}
Abstrak
Perkembangan teknologi komunikasi pada saat ini maju dengan pesat. Salah satu adalah perkembangan alat komunikasi berupa telepon selular. Telpon yang pada awalnya ditemukan sebagai alat media menyampaikan pesan suara dan alat komunikasi sekarang berkembang pesat. Telepon selular kini berganti nama menjadi smartphone atau telpon pintar. Kita bisa melakukan banyak hal dalam smartphone selain berkomunikasi lewat suara dan pesan. Kita bisa menambahkan berbagai aplikasi di smartphone, misalnya Whatsapp, TikTok, Facebook, Twitter, Instagram dan lain-lain. Selain itu smartphone juga bisa digunakan untuk browsing berita atau info terkini, bermain game online, belanja online bahkan smartphone juga bisa dimanfaatkan untuk bekerja.Kecanduan smartphone adalah tindakan yang tidak bisa mengontrol penggunaan smartphone dengan kata lain hidup kita di bawah kendali smartphone. Hal ini sangat menjangkiti para remaja. Remaja menghabiskan sebagian besar waktu dihadapan smartphone. Interaksi dengan orang lain terasa berbeda. Ada istilah menjauhkan yang dekat, mendekatkan yang jauh. Dengan keadaan yang seperti ini, penulis tertantang untuk mengadakan penelitian tentang mereduksi kecanduaan smartphone pada siswa SMKN 1 Bandung melalui layanan konseling individu dengan teknik kontrak perilaku.Penelitian ini menerapkan Penelitian Tindakan Bimbingan dan Konseling (PTBK) dengan dua siklus. Hasil dari penelitian kecanduan smartphone siswa dapat direduksi melalui konseling individu dengan 21eknik kontrak perilaku. Hal ini terlihat dari hasil angket penggunaan smartphone oleh siswa. Pada siklus I skor angket 77 termasuk kategori 'sangat aktif'. Pada siklus II skor tersebut mengalami penurunan menjadi 43 termasuk dalam kategori 'cukup aktif'.Penelitian ini diharapkan mampu memberikan masukan pada konselor sebagai praktisi lapangan, yaitu layanan konseling individu dengan teknik kontrak perilaku dapat mereduksi kecanduan smartphone pada siswa.

Kata Kunci: Kecanduan Smartphone, Konseling Individu, Kontrak Perilaku
\end{abstract}

\begin{abstract}
The development of communication technology is currently advancing rapidly. One of them is the development of communication tools in the form of cellular telephones. The telephone which was originally invented as a medium for conveying voice messages and means of communication is now growing rapidly. Cellular phones are now changing their names to smartphones or smart phones. We can do many things on a smartphone apart from communicating via voice and messages. We can add various applications on smartphones, for example Whatsapp, TikTok, Facebook, Twitter, Instagram and others. In addition, smartphones can also be used to browse the latest news or info, play online games, shop online, and even smartphones can also be used for work. Smartphone addiction is an action that cannot control the use of smartphones in other words our lives are under the control of
\end{abstract}


Jurnal HELPER, Vol 36 No 1 (2019) 21 - 26

Bimbingan dan Konseling Universitas PGRI Adi Buana Surabaya

ISSN: 02162938

smartphones. This really affects teenagers. Teens spend most of their time in front of smartphones. Interaction with other people feels different. There is a term that draws near, brings closer together. With this kind of situation, the author is challenged to conduct research on reducing smartphone addiction to students of SMKN 1 Bandung through individual counseling services with the behavior contract technique. This study applies the Guidance and Counseling Action Research (PTBK) with two cycles. The results of the research on student smartphone addiction can be reduced through individual counseling with the behavior contract technique. This can be seen from the results of a questionnaire on the use of smartphones by students. In the first cycle the questionnaire score was 77 in the category of "very active". In the second cycle the score decreased to 43, which was included in the "moderately active' category. This research is expected to be able to provide input to counselors as field practitioners, namely that individual counseling services with behavioral contract techniques can reduce smartphone addiction in students.

Key Words: Smartphone Addiction, Individual Counseling, Behavior Contract

\section{LATAR BELAKANG}

Era industry 4.0 membawa dampak yang luar biasa bagi kehidupan manusia. Dampak dalam Pendidikan, perkembangan teknologi, perkembangan pola kerja dan sebagainya. Hal ini berdampak terhadap pola pikir, pola sikap, pola kebiasaan manusia. Kita dimudahkan dengan sesuatu yang instan, cepat dan praktis.

Perkembangan teknologi yang tidak bisa dihindari adalah smartphone. Mau tidak mau saat ini kita harus menggunakan smartphone untuk menunjang kebutuhan akan komunikasi dan informasi. Bahkan saat ini proses pembelajaran juga memanfaatkan platform, sehingga kita membutuhkan gadget terutama smartphone (siswa) untuk dapat mengakses pembelajaran daring.

Siswa menggunakan sebagian besar waktu mereka dihadapan smartphone. Hal ini berdasarkan observasi penulis saat melakukan kegiatan bimbingan klasikal, saat ada jam kosong pasti siswa bermain dengan smartphone. Saat pergantian jam pelajaran siswa menyempatkan melihat smartphone, siswa enggan menaruh smartphonenya di kotak tempat HP. Guru harus menegur agar siswa menghentikan aktivitas bermain smartphone. Ketika penulis bertanya kepada siswa, apa yang dilakukan saat bangun dan akan tidur, jawaban sebagian besar siswa adalah bermain smartphone. Hasil need assessment yang penulis lakukan terhadap siswa kelas XII TEI 1 menyatakan $67 \%$ sangat aktif menggunakan smartphone dan 33\% aktif menggunakan smartphone. Hasil penelitian Wulandari, dkk (2014: 406), menunjukkan bahwa alasan utama menggunakan smartphone adalah untuk berkomunikasi, yaitu sebesar $45,57 \%$ dan sebesar 21,01\% untuk pergaulan.

Terdapat berbagai teknik dalam melakukan proses konseling. Salah satunya adalah teknik kontrak perilaku. Ratna (2013: 66) kontrak perilaku merupakan persetujuan dan hasil kesepakatan oleh dua orang atau lebih (konselor dan konseli) yang bertujuan untuk mengubah perilaku konseli dan bila konseli mampu mengubah perilakunya, maka konseli akan menerima reward. Konselor membantu konseli untuk mereduksi kecanduaan 
Jurnal HELPER, Vol 36 No 1 (2019) 21 - 26

Bimbingan dan Konseling Universitas PGRI Adi Buana Surabaya

ISSN: 02162938

smartphone dengan menerapkan teknik kontrak perilaku. Kontrak perilaku digunakan sebagai tuntunan konseli untuk melakukan aktivitasaktivitas yang dapat mereduksi kecanduan smartphone. Berdasarkan fenomena tersebut, maka penulis berkeinginan untuk melakukan penelitian dengan judul "Mereduksi Kecanduan Smartphone melalui Layanan Konseling Individu dengan Teknik Kontrak Perilaku Siswa XII TEI 1 SMKN 1 Bandung Kabupaten Tulungagung.

\section{METODOLOGI}

Penulis menggunakan jenis penelitian yang mengacu pada model Kemmis dan McTaggart. Penelitian tindakan model Kemmis dan McTaggart terdiri atas empat komponen, yaitu perencanaan, pelaksanaan tindakan, observasi dan refleksi. Penelitian ini dilaksanakan dalam dua siklus.

Penelitian tindakan adalah penelitian yang dilakukan profesional dengan melakukan tindakan tertentu untuk memperbaiki dan meningkatkan kualitas praktik profesional tersebut (Gall, Gall \& Borg, 2003; Schmuck, 2007; dalam Ramli). Adapun penelitian tindakan dalam Bimbingan dan Konseling merupakan penelitian yang dilaksanakan konselor melalui tindakan tertentu untuk memperbaiki dan meningkatkan kualitas praktik layanan bimbingan dan konseling (Gall, Gall \& Borg, 2003; Nuttal \&Ivey, 1987; dalam Ramli).

Subjek penelitian ini adalah siswa kelas

XII TEI 1 SMKN 1 Bandung, yang beralamat di desa Bantengan, Kecamatan Bandung, Kabupaten Tulungagung. Subjek penelitian sebanyak 1 siswa. Penelitian dilaksanakan di SMKN 1 Bandung. Penelitian ini dilakukan pada semester ganjil tahun ajaran 2018/2019 yaitu pada bulan Agustus 2018.

Angket terdiri dari 20 pernyataan. Skala pengukuran angket menggunakan skala pengukuran yang dikembangkan oleh Likert. Skala yang digunakan adalah SS (Sangat Sesuai), S (Sesuai), KS (Kurang Sesuai) dan TS (Tidak Sesuai). Skor yang diberikan pada tiap skala adalah SS diberi skor 4, S diberi skor 3, KS diberi skor 2 dan TS diberi skor 1 . Penghitungan skor adalah Skor total $=$ skor item $1+$ skor item $2+\ldots . .+$ skor item 20. Kriteria skor dari angket adalah 20-34 = kurang aktif, 35-49 = cukup aktif, 50-64 = aktif dan 65-80 = sangat aktif.

Angket yang digunakan dalam penelitian ini diadopsi dari angket penelitian tentang penggunaan dan adiksi smartphone di kalangan mahasiswa fakultas kedokteran Universitas Hasanuddin angkatan 2015 dan 2016. Penelitian ini diadakan oleh Lukman, salah satu mahasiswa kedokteran di Universitas Hasanuddin. Pada penelitian tersebut dijelaskan bahwa hasil analisis menggunakan cronbach's alpha melalui SPSS diperoleh nilai alpha 0.793. Setelah dibandingkan dengan nilai tabel signifikansi diperoleh hasil nilai alpha $>0.632$. Jadi dapat dikatakan bahwa kuesioner tersebut reliable atau terpercaya sebagai alat pengumpul data.

Pedoman observasi keterlaksanaan layanan konseling individu menggunakan instrumen asesmen proses yang terdiri dari 25 item. Pedoman penskoran adalah bila dijawab YA mendapat skor 4, bila dijawab TIDAK 
Jurnal HELPER, Vol 36 No 1 (2019) 21 - 26

Bimbingan dan Konseling Universitas PGRI Adi Buana Surabaya

ISSN: 02162938

mendapat skor 0 . Penghitungan skor $4 \mathrm{x}$ item dengan jawaban YA. Kriteria skor adalah skor 25-43 = kurang, 44-62 = sedang, skor 63-81 = baik dan skor 82-100 = sangat baik.

Pedoman observasi keefektifan konseling individu menggunakan instrumen asesmen hasil. Instrumen asesmen hasil terdiri dari 6 item. Pedoman penskoran menggunakan skala SS (Sangat Sesuai), S (Sesuai), KS (Kurang Sesuai) dan TS (Tidak Sesuai). Skor yang diberikan pada tiap skala adalah SS diberi skor 4, S diberi skor 3, KS diberi skor 2 dan TS diberi skor 1. Penghitungan skor adalah Skor total $=$ skor item $1+$ skor item $2+\ldots . .+$ skor item 6. Kriteria skor dari pedoman keefektifan konseling individu adalah 6-11 = cukup baik, 12-17 = baik dan 18-24 = sangat baik.

Teknik analisa yang digunakan adalah teknik analisis kualitatif oleh Miles dan Huberman, yaitu teknik analisis interaktif. Analisa interaktif terdiri atas tiga komponen, yaitu reduksi data, paparan data serta penarikan kesimpulan (Susilo, 2009:53).

\section{HASIL PENELITIAN}

Kegiatan yang dilakukan sebelum melaksanakan konseling individu adalah pengisian angket kecanduan siswa terhadap smartphone. Berdasarkan hasil pengisian angket, konseli mendapatkan skor 77. Skor tersebut masuk dalam kategori sangat aktif dalam penggunaan smartphone.

Hasil observasi pada siklus I meliputi observasi keterlaksanaan konseling individu dan keefektifan konseling individu untuk mereduksi kecanduan smartphone. Hasil skor keterlaksanaan konseling individu pada siklus I mendapatkan skor 60 termasuk dalam kriteria ‘sedang'. Dalam konseling siklus I hanya terungkap jika permasalahan konseli adalah kecanduan smartphone kemudian konselor memberikan strategi-strategi untuk mengurangi kecanduan smartphone. Dalam hal ini konselor perlu mengidentifikasi lebih dalam terkait permasalahan konseli. Skor keterlaksanaan konseling individu siklus II mendapatkan skor 80. Skor 80 termasuk dalam kriteria 'baik'. Skor keterlaksanaan konseling individu siklus II mengalami peningkatan dibandingkan dengan siklus I. Pada siklus I memperoleh skor 60 termasuk dalam kriteria 'sedang'. Skor ini meningkat pada siklus II menjadi 80 termasuk dalam kriteria 'baik'.

Skor keefektifan konseling individu untuk mereduksi kecanduan smartphone mendapatkan skor 16. Skor ini masuk ke dalam kategori ‘baik'. Meskipun demikian ada beberapa item yang diisi skor '2' dengan kategori kurang sesuai. Item tersebut adalah Saya dapat merumuskan cara-cara mengurangi kecanduan smartphone setelah mengikuti konseling individu dan Saya lebih mampu dan percaya diri dalam menghadapi dan memecahkan masalah yang saya alami setelah saya mengikuti konseling individu. Keefektifan konseling individu untuk mereduksi kecanduan smartphone di siklus II mendapatkan skor 23. Skor ini masuk ke dalam kategori 'sangat baik'. Hasil observasi keefektifan konseling individu pada siklus II mengalami peningkatan jika dibandingkan dengan siklus I.

Berdasarkan pengisian angket pada akhir siklus II diketahui bahwa penggunaan smartphone pada konseli memperoleh skor 43. 
Jurnal HELPER, Vol 36 No 1 (2019) 21 - 26

Bimbingan dan Konseling Universitas PGRI Adi Buana Surabaya

ISSN: 02162938

Skor 43 masuk dalam kategori 'cukup aktif'.

Konseli menjawab item dengan skor bervariasi dari skor 1 (kurang sesuai), 2 (cukup sesuai) dan 3 (sesuai).

\section{PEMBAHASAN}

Pada siklus I skor pengisian angket adalah 77 dengan kategori 'sangat aktif', sedangkan pada siklus II skor pengisian angket turun menjadi 43 dengan kategori 'cukup aktif'. Reduksi kecanduan smartphone siswa dilakukan melalui konseling individu dengan teknik kontrak perilaku. Konseling individu merupakan suatu proses bantuan secara profesional antara konselor dan konseli untuk membantu individu (konseli) dalam memecahkan masalahnya agar individu dapat menyesuaikan diri dengan lingkungannya sesuai potensi atau kemampuan yang ada dalam dirinya. Dalam konseling individu, konselor menerapkan teknik kontrak perilaku. Ratna (2013:66) kontrak perilaku adalah persetujuan dan hasil kesepakatan oleh dua orang atau lebih (konselor dan konseli) yang bertujuan untuk mengubah perilaku konseli dan bila konseli mampu mengubah perilakunya, maka konseli akan menerima reward. Konselor dan konseli memilih perilaku yang realistik dan dapat diterima oleh kedua belah pihak. Melalui Teknik kontrak perilaku, konselor dapat membantu siswa dalam mereduksi kecanduan smartphone. Hal ini dikatakan demikian karena tujuan dari kontrak perilaku adalah untuk mmengubah perilaku konseli yang tidak adaptif menjadi perilaku adaptif. Konseli membuat kontrak perilaku yang berisikan jika ada waktu luang di rumah akan digunakan untuk membaca buku atau membantu pekerjan ibu, menggunakan smartphone seperlunya dan sering berinteraksi dengan orang tua serta teman. Jika konseli berhasil mengurangi kecanduannya terhadap smartphone sebagai reward berlibur dengan keluarga. Konseli melakukan strategi mereduksi kecanduan terhadap smartphone dengan sungguhsungguh. Sehingga penerapan teknik kontrak perilaku dapat mereduksi kecanduan konseli terhadap smartphone.

\section{KESIMPULAN}

Berdasarkan hasil penelitian yang telah dilakukan dan pembahasan hasil penelitian, maka penulis dapat menyimpulkan kecanduan siswa terhadap smartphone dapat direduksi dengan teknik kontrak perilaku.

Hasil dari penelitian ini masih sangat jauh dari kata sempurna, maka saran untuk semua pihak adalah terus mengembangkan dan mengupdate kemampuan dalam melakukan dan menerapkan teknik dan teori konseling dalam membantu menyelesaikan masalah konseli.

\section{DAFTAR PUSTAKA}

Abidin, Zainal. (2009). Optimalisasi Konseling Individu Dan Kelompok Untuk Keberhasilan Siswa. Jurnal Pemikiran Alternatif Pendidikan.

Lukman, 2018. Penggunaan dan Adiksi Smartphone di Kalangan Mahasiswa Fakultas Kedokteran Universitas Hasanuddin Angkatan 2015 dan 2016. Skripsi. Makasar: Fakultas Kedokteran Universitas Hasanuddin

Ramli, M.2008. Penelitian Tindakan dalam Bimbingan dan Konseling. Materi disajikan dalam Pelatihan Penelitian Tindakan bagi Konselor di kabupaten Gresik. 
Jurnal HELPER, Vol 36 No 1 (2019) 21 - 26

Bimbingan dan Konseling Universitas PGRI Adi Buana Surabaya

ISSN: 02162938

Ratna, Lilis. 2013. Teknik-teknik Konseling. Sleman: Deeplublish.

Susilo, H., dkk. 2009. Penelitian Tindakan Kelas. Malang: Bayumedia.

Wulandari, dkk. 2014. Survey Deskriptif Optimalisasi Penggunaan Smartphone
Di Kalangan Mahasiswa Dan Siswa Se-Kota Singaraja. Jurnal Penelitian. 3 (6): 401-410. (Online), (https://ejournal.undiksha.ac.id/index.p hp/KP/article/view/19769, diakses 16 Agustus 2018). 